\title{
Calcium and Calmodulin Involve in Mycorrhizal and Root Development in Trifoliate Orange Colonized by Rhizophagus intraradices
}

\author{
Qiang-Sheng WU*, Qiu-Dan NI, Yan-Cong QUE, Wei HUANG \\ Yangtze University, College of Horticulture and Gardening/Institute of Root Biology, Jingzhou, Hubei 434025, \\ People'sRepublic ofChina; wuqiangsh@163.com (*correspondingauthor)
}

\begin{abstract}
A pot experiment was made to study effects of ethylene glycol tetraacetic acid (EGTA, an inhibitor of $\mathrm{Ca}^{2+}$ ) and trifluoperazine (TFP, an inhibitor of calmodulin (CaM) on mycorrhizal colonization, growth performance, and chlorophyll, sucrose and glucose concentrations of four-month-old trifoliate orange (Poncirus trifoliata) seedlings under mycorrhization with Rhizophagus intraradices. Exogenous EGTA and TFP notably inhibited root mycorrhizal colonization, and the addition of EGTA also decreased soil hyphal length. In general, EGTA treatment decreased but TFP increased easily extractable glomalin-related soil protein (EE-GRSP) and total GRSP (T-GRSP) concentrations. In addition, EGTA and TFP applications generally significantly inhibited growth performance (height, stem diameter, leaf number, and shoot and root biomass), root traits (total length, surface area, volume, and number of $1^{\text {st }}, 2^{\text {nd }}$ and $3^{\text {rd }}$ order lateral root), and chlorophyll $a, b$ and $a+b$ concentrations, the mycorrhizal inoculation generally reversed the negative effects and markedly increased these variables, irrespective of whether the seedlings were applied by inhibitors or not. EGTA and TFP treatments generally inhibited sucrose and glucose levels of leaf and root, except that TFP application notably increased root glucose in AM and non-AM seedlings. AMF inoculation resulted in carbohydrate modification: decrease in leaf sucrose, increase in root sucrose and leaf glucose, as well increase in root glucose under no-inhibitor and EGTA conditions and decrease in root glucose under TFP. It suggests that $\mathrm{Ca}^{2+}$ and $\mathrm{CaM}$ were involved in mycorrhizal and root development in trifoliate orange.
\end{abstract}

Keywords: arbuscular mycorrhizal fungi, ethylene glycol tetraacetic acid, roots, trifluoperazine

\begin{abstract}
Abbreviations: AM, arbuscular mycorrhiza; AMF, arbuscular mycorrhizal fungi; CaM, calmodulin; EE-GRSP, easily extractable glomalin-related soil protein; EGTA, ethylene glycol tetraacetic acid; GRSP, glomalin-related soil protein; TFP, trifluoperazine; T-GRSP, total glomalin-related soil protein
\end{abstract}

\section{Introduction}

Arbuscular mycorrhizal fungi (AMF), one of the most widespread endophytic microorganisms in soil, can establish symbiotic association, namely, arbuscular mycorrhizas (AMs), with the roots of most terrestrial plants. AM symbiosis can provide roots of the host with plenty of water and mineral nutrition from the soil (Wu et al., 2011), in requital for up to $30 \%$ of the host's photosynthates for AM development (Kivlin et al., 2011). During the formation and development of AM symbiosis, many diffusible symbiotic signals such as a mixture of sulphated and nonsulphated simple lipochitooligosaccharides are involved in the initial communication between AMF and the fungal partner, while the exact signal molecules are not well known (Harrison, 2005; Maillet et al., 2011).

Calcium $\left(\mathrm{Ca}^{2+}\right)$ is considered as an universal second messenger in the signal transduction networks to induce a series of extracellular stimuli with particular physiological process (Hetherington and Brownlee, 2004; Dodd et al., 2010). Plant cells receive the diffusible signals released by spore and extraradical mycelium of AMF to stimulate a $\mathrm{Ca}^{2+}$ dependent pathway (Navazio et al., 2007; Navazio and Mariani, 2008). Spores of Gigaspora margarita were able to release some active molecules to arouse a $\mathrm{Ca}^{2+}$-mediated signaling, thus, leading to the AM symbiosis-specific responses (Navazio et al., 2007). As reported by Breuninger and Requena (2004), some genes related to $\mathrm{Ca}^{2+}$-dependent signaling were up-regulated during interaction between AMF and plants, implying that $\mathrm{Ca}^{2+}$ as an intracellular messenger plays an important role in early stages of AM formation (Navazio et al., 2007). Calmodulin (CaM) is a small and broadly distributed $\mathrm{Ca}^{2+}$-binding protein, which is related with signal pathways and adventitious rooting (Liao et al., 2012). It is not well known whether the CaM mediated mycorrhizal and root development. 
381

Plant roots generally possess various physiological functionings including water and nutrient uptake, anchorage to the soil, and tolerance capacity of abiotic and biotic stresses (Lopez-Bucio et al., 2003). Emerging evidence implicates that root development is involved in signal transduction (Zamioudis et al., 2013). Wu et al. (2012) have shown that AMF mediated the root morphology in citrus plants through the endogenous polyamine metabolism. Even so, the AM-mediated mechanisms of root morphology are not yet fully understood. Liao et al. (2012) reported that $\mathrm{Ca}^{2+}$ might act as an upstream regulator for $\mathrm{CaM}$ in the process of adventitious rooting. In addition, CaM mainly distributed in cortical microtubules of root meristematic zone and in the root tip (Fraichard et al., 1996).

Citrus, one of the most important fruit trees, is widely planted in the world including the Southern regions of China and strongly depends on AMs due to short and poor root hairs (Wu et al., 2013a). The objective of the present work was to investigate the influences of exogenous $\mathrm{Ca}^{2+} / \mathrm{CaM}$ inhibitors on plant growth, carbohydrate concentrations, and AM and root development in citrus seedlings.

\section{Materials and methods}

\section{Plant culture}

After sterilized with $70 \%$ alcohol for 15 min, seeds of trifoliate orange [Poncirus trifoliata (L.) Raf.] were germinated in plastic boxes containing autoclaved sands in a controlled growth chamber, where day/night temperature is $28 / 20{ }^{\circ} \mathrm{C}$, photosynthetic photon flux density 745 $\mu \mathrm{mol} / \mathrm{m}^{2} / \mathrm{s}$, and relative humidity $80 \%$. The five-leaf-old seedlings with similar size and non-mycorrhization were transferred into a plastic pot $(13 \mathrm{~cm}$ in depth and $15.5 \mathrm{~cm}$ in mouth diameter) containing the autoclaved $(0.11 \mathrm{MPa}, 121$ $\left.{ }^{\circ} \mathrm{C}, 40 \mathrm{~min}\right)$ substrates of yellow soil and vermiculite $(2: 1$, $\mathrm{v} / \mathrm{v}$ ) on March 15, 2012. The AMF inoculated pots received $50 \mathrm{~g}$ inoculums of Rhizophagus intraradices (N.C. Schenck \& G.S. Sm.) C. Walker \& A. Schüßler at $5 \mathrm{~cm}$ soil depth, and the non-AMF pots also received the same quantity sterilized inoculums as the control. The fungal strain was isolated from the rhizosphere of Lycopersicon esculentum in Chaoyang District, Beijing. The AM fungus was propagated with Sorghum vulgare as the host for 16 weeks under pot culture in terms of the identified spores, and the inocula were comprised of both spores (35 spores/g) and sands (root AM colonization was $89 \%$ at harvest). The AM and non-AM seedlings were grown in a plastic greenhouse of Yangtze University (Jingzhou, China) from March to July 2012 .

After 16 weeks of acclimation or AMF inoculation, 250 $\mathrm{mL} \quad 0.5 \mathrm{mM}$ ethylene glycol-bis ( $\beta$-aminoethyl ether)$\mathrm{N}, \mathrm{N}, \mathrm{N}^{\prime}, \mathrm{N}^{\prime}$-tetraacetic acid (EGTA, an inhibitor of $\mathrm{Ca}^{2+}$, from Tianda Chemical Reagent Factory, Tianjin, China) and $150 \mu \mathrm{M}$ trifluoperazine (TFP, an inhibitor of $\mathrm{CaM}$, from SIGMA-ALDRICH) were exogenously applied to the designed pots at an interval of two days from June 7 to July 23 , respectively. Meanwhile, the other pots received $250 \mathrm{~mL}$ distilled water as the control.

\section{Experimental design}

In a $3^{2}$ completely randomized arrangement, six treatments with three replicates each for a total of 18 pots (two seedlings/pot) were as follows: (i) non-AMF control (-AMF), (ii) AM $R$. intraradices only (+AMF), (iii) EGTA plus $R$. intraradices (EGTA+AMF), (iv) EGTA only (EGTA-AMF), (v) TFP plus $R$. intraradices (TFP+AMF), and (vi) TFP only (TFP-AMF).

\section{Measurements of plant growth and root traits}

After twenty times of EGTA and TFP applications, the $A M$ and non-AM seedlings were harvested, and plant height, stem diameter, and leaf number per plant were directly recorded. And then, these seedlings were divided into shoots and roots, and the number of $1^{1^{\mathrm{s}}}-2^{\text {nd }}$-, and $3^{\text {rd }}-$ order lateral roots was determined by means of manual count. The root systems per seedlings were scanned with an Epson scanner, and total length, surface area and volume were automatically obtained by a professional WinRHIZO root analysis system. The dry biomass of shoots and roots was determined after $75^{\circ} \mathrm{C}$ for $48 \mathrm{~h}$.

\section{Measurements of mycorrbizal development}

Root mycorrhizas were stained with the procedure reported by Phillips and Hayman (1970), and the root AM colonization was expressed as the percentage of colonized root lengths versus observed root lengths. Soil hyphal length was determined by the protocol described by Bethlenfalvay and Ames (1987).

The easily extractable glomalin-related soil protein (EEGRSP) and total GRSP (T-GRSP) were done following the method of Zou et al. (2014).

\section{Determinations of chlorophyll and sugar concentrations}

The concentration of chlorophyll $a$ and $b$ was determined using the method described by Lichtenthaler and Wellburn (1983).

Glucose and sucrose of leaves and roots were extracted with $80 \%$ of ethanol and determined with the colorimetric method of Zhang and Zai (2004).

\section{Statistical analysis}

The data were analyzed by one-way ANOVA with SAS software, and the Duncan's multiple range test was used to compare the significant differences between the treatments at the $5 \%$ level.

\section{Results}

\section{Mycorrbizal development}

Root AM colonization varied from 22.81 to $32.05 \%$ in the inoculated seedlings, whereas no AMF colonization was found in the non-inoculated seedlings (Tab. 1). Compared to sole AMF treatment, application of EGTA or TFP significantly inhibited root AM colonization by 29 or $25 \%$, respectively. In addition, in the AM seedlings, EGTA treatment significantly decreased soil hyphal length but TFP did not alter the parameter (Tab. 1).

In general, the AM seedlings recorded significantly higher rhizospheric EE-GRSP and T-GRSP concentrations 
Tab. 1. Mycorrhizal development of Rhizophagus intraradices - colonized trifoliate orange (Poncirus trifoliata) seedlings applied by EGTA and TFP

\begin{tabular}{|c|c|c|c|c|}
\hline \multirow{2}{*}{ Treatment } & \multirow{2}{*}{ Root AM colonization (\%) } & \multirow{2}{*}{$\begin{array}{l}\text { Soil hyphal length } \\
(\mathrm{m} / \mathrm{g} F W)\end{array}$} & \multicolumn{2}{|c|}{ Rhizospheric GRSP (mg/g DW) } \\
\hline & & & EE-GRSP & T-GRSP \\
\hline$-\mathrm{AMF}$ & 0 & 0 & $0.69 \pm 0.02^{c}$ & $0.97 \pm 0.03^{c}$ \\
\hline$+\mathrm{AMF}$ & $32.05 \pm 3.5^{3 a}$ & $0.21 \pm 0.02^{\mathrm{a}}$ & $0.79 \pm 0.01^{\mathrm{b}}$ & $1.19 \pm 0.01^{\mathrm{a}}$ \\
\hline EGTA-AMF & 0 & 0 & $0.63 \pm 0.02^{\mathrm{d}}$ & $0.89 \pm 0.03^{\mathrm{d}}$ \\
\hline $\mathrm{EGTA}+\mathrm{AMF}$ & $22.81 \pm 1.04^{\mathrm{b}}$ & $0.10 \pm 0.01^{b}$ & $0.70 \pm 0.01^{\mathrm{c}}$ & $1.06 \pm 0.03^{\mathrm{b}}$ \\
\hline TFP-AMF & 0 & 0 & $0.74 \pm 0.04^{\mathrm{bc}}$ & $1.04 \pm 0.04^{\mathrm{b}}$ \\
\hline TFP+AMF & $23.91 \pm 1.30^{\mathrm{b}}$ & $0.21 \pm 0.02^{\mathrm{a}}$ & $0.85 \pm 0.05^{\mathrm{a}}$ & $1.24 \pm 0.05^{\mathrm{a}}$ \\
\hline
\end{tabular}

Same letter within each column indicates no significant difference among treatments $(\mathrm{P}<0.05)$

than the non-AM seedlings, irrespective of exogenous inhibitor types (Tab. 1). Compared to the no-inhibitor treatment, EGTA application significantly decreased rhizospheric EE-GRSP and T-GRSP concentrations in AM or non-AM seedlings, whilst TPF significantly increased rhizospheric EE-GRSP concentration in AM seedlings and rhizospheric T-GRSP concentration in non-AM seedlings.

\section{Growth performance}

Mycorrhizal inoculation significantly increased plant height, stem diameter, and shoot and root dry biomass than non-mycorrhizal treatment, irrespective of exogenous inhibitors applied or not (Tab. 2). The AMF treatment and the inhibitor applications did not alter leaf number per seedling. In the non-AM seedlings, EGTA significantly decreased stem diameter and shoot dry biomass, and TPF significantly inhibited shoot and root dry biomass production. In the AM seedlings, both EGTA and TFP significantly decreased plant height, stem diameter, and shoot and root dry biomass, except a similar root dry biomass between TFP+AMF treatment and +AMF treatment.

\section{Root morphological traits}

Compared to non-AMF control, AMF inoculation generally significantly increased root total length, surface area, volume, and number of $1^{\text {st }}-, 2^{\text {nd }}$ - and $3^{\text {rd }}$-order lateral roots, irrespective of the inhibitors applied or not, except a similar $1^{\text {st }}$-order lateral root number between $+\mathrm{AMF}$ and AMF and between TFP+AMF and TFP-AMF (Tab. 3). In the non-AM seedlings, EGTA significantly decreased total length, surface area, volume, and $1^{\text {st }}$-order lateral root number, and TFP significantly decreased total length, surface area, and $1^{\text {st }}-, 2^{\text {nd }}-$ and $3^{\text {rd }}-$ order lateral root number. In the AM seedlings, EGTA significantly inhibited total length, surface area, and first-order lateral root number, and TFP notably inhibited $1^{\text {st }}-, 2^{\text {nd }}$ - and $3^{\text {rd }}$-order lateral root number.

\section{Chlorophyll concentrations}

Mycorrhizal seedlings showed significantly higher chlorophyll $a, b$, and $a+b$ concentrations than nonmycorrhizal seedlings, regardless of exogenous inhibitors or not (Tab. 4), except that chlorophyll $b$ concentration was

Tab. 2. Effect of EGTA and TFP on growth performance of trifoliate orange (Poncirus trifoliata) seedlings inoculated with and without Rhizophagus intraradices

\begin{tabular}{|c|c|c|c|c|c|}
\hline \multirow{2}{*}{ Treatment } & \multirow{2}{*}{ Plant height $(\mathrm{cm})$} & \multirow{2}{*}{ Leaf number } & \multirow{2}{*}{ Stem diameter $(\mathrm{mm})$} & \multicolumn{2}{|c|}{ Dry biomass (g/plant) } \\
\hline & & & & Shoot & Root \\
\hline$-\mathrm{AMF}$ & $20.1 \pm 2.0^{\mathrm{bcd}}$ & $20.0 \pm 1.0^{\mathrm{a}}$ & $2.18 \pm 0.04^{c}$ & $0.86 \pm 0.06^{\mathrm{b}}$ & $0.30 \pm 0.02^{b c}$ \\
\hline$+\mathrm{AMF}$ & $25.3 \pm 1.6^{\mathrm{a}}$ & $20.3 \pm 2.1^{\mathrm{a}}$ & $2.59 \pm 0.04^{\mathrm{a}}$ & $0.99 \pm 0.04^{\mathrm{a}}$ & $0.43 \pm 0.02^{\mathrm{a}}$ \\
\hline EGTA-AMF & $18.6 \pm 1.0^{\mathrm{cd}}$ & $19.0 \pm 2.0^{\mathrm{a}}$ & $1.96 \pm 0.06^{\mathrm{d}}$ & $0.70 \pm 0.04^{c}$ & $0.26 \pm 0.02^{\mathrm{cd}}$ \\
\hline $\mathrm{EGTA}+\mathrm{AMF}$ & $22.3 \pm 1.3^{\mathrm{b}}$ & $19.7 \pm 1.5^{\mathrm{a}}$ & $2.34 \pm 0.10^{\mathrm{b}}$ & $0.81 \pm 0.05^{b}$ & $0.32 \pm 0.02^{b}$ \\
\hline TFP-AMF & $18.2 \pm 1.1^{\mathrm{d}}$ & $18.3 \pm 2.1^{\mathrm{a}}$ & $2.08 \pm 0.06^{\mathrm{cd}}$ & $0.41 \pm 0.03^{d}$ & $0.24 \pm 0.03^{d}$ \\
\hline $\mathrm{TFP}+\mathrm{AMF}$ & $20.8 \pm 0.8^{\mathrm{bc}}$ & $20.7 \pm 1.2^{\mathrm{a}}$ & $2.45 \pm 0.09^{\mathrm{b}}$ & $0.77 \pm 0.09^{\mathrm{bc}}$ & $0.40 \pm 0.03^{\mathrm{a}}$ \\
\hline
\end{tabular}

Same letter within each column indicates no significant difference among treatments $(\mathrm{P}<0.05)$

Tab. 3. Effects of EGTA and TFP on root morphological traits of trifoliate orange (Poncirus trifoliata) seedlings inoculated with and without Rhizophagus intraradices

\begin{tabular}{ccccccc}
\hline \multirow{2}{*}{ Treatment } & \multirow{2}{*}{ Total length $(\mathrm{cm})$} & \multirow{2}{*}{ Surface area $\left(\mathrm{cm}^{2}\right)$} & \multirow{2}{*}{ Volume $\left(\mathrm{cm}^{3}\right)$} & \multicolumn{3}{c}{ Number of lateral root } \\
\cline { 5 - 6 } & & & & $1^{\text {st }}$-order & $2^{\text {nd }}$-order & $3^{\text {rd }}$-order \\
\hline -AMF & $239 \pm 9^{\mathrm{c}}$ & $33.6 \pm 2.5^{\mathrm{c}}$ & $0.38 \pm 0.04^{\mathrm{c}}$ & $43 \pm 5^{\mathrm{ab}}$ & $78 \pm 2^{\mathrm{bc}}$ & $10 \pm 1^{\mathrm{c}}$ \\
+AMF & $455 \pm 26^{\mathrm{a}}$ & $56.3 \pm 3.4^{\mathrm{a}}$ & $0.56 \pm 0.05^{\mathrm{b}}$ & $47 \pm 2^{\mathrm{a}}$ & $102 \pm 9^{\mathrm{a}}$ & $16 \pm 2^{\mathrm{a}}$ \\
EGTA-AMF & $206 \pm 16^{\mathrm{d}}$ & $27.6 \pm 2.5^{\mathrm{d}}$ & $0.29 \pm 0.07^{\mathrm{d}}$ & $28 \pm 1^{\mathrm{e}}$ & $63 \pm 7^{\mathrm{cd}}$ & $9 \pm 2^{\mathrm{cd}}$ \\
EGTA+AMF & $378 \pm 11^{\mathrm{b}}$ & $49.7 \pm 2.9^{\mathrm{b}}$ & $0.52 \pm 0.05^{\mathrm{b}}$ & $40 \pm 3^{\mathrm{bc}}$ & $88 \pm 11^{\mathrm{ab}}$ & $14 \pm 2^{\mathrm{b}}$ \\
TFP-AMF & $202 \pm 17^{\mathrm{d}}$ & $29.0 \pm 1.4^{\mathrm{d}}$ & $0.33 \pm 0.02^{\mathrm{cd}}$ & $32 \pm 3^{\mathrm{de}}$ & $60 \pm 6^{\mathrm{d}}$ & $6 \pm 3^{\mathrm{d}}$ \\
TFP+AMF & $428 \pm 18^{\mathrm{a}}$ & $58.4 \pm 0.8^{\mathrm{a}}$ & $0.64 \pm 0.04^{\mathrm{a}}$ & $36 \pm 1^{\text {cd }}$ & $77 \pm 13^{\mathrm{bc}}$ & $11 \pm 1^{\mathrm{bc}}$ \\
\hline
\end{tabular}

Same letter within each column indicates no significant difference among treatments $(\mathrm{P}<0.05)$ 
Tab. 4. Effects of EGTA and TFP on chlorophyll $a, b$ and $a+b$ concentrations and sucrose and glucose concentrations in leaf and root of trifoliate orange (Poncirus trifoliata) seedlings inoculated with and without Rhizophagus intraradices

\begin{tabular}{|c|c|c|c|c|c|c|c|}
\hline \multirow{2}{*}{ Treatment } & \multicolumn{3}{|c|}{ Chlorophyll (mg/g FW) } & \multicolumn{2}{|c|}{ Sucrose (mg/g DW) } & \multicolumn{2}{|c|}{ Glucose (mg/g DW) } \\
\hline & $a$ & $b$ & $a+b$ & Leaf & Root & Leaf & Root \\
\hline$-\mathrm{AMF}$ & $1.67 \pm 0.11^{b}$ & $0.62 \pm 0.07^{b}$ & $2.29 \pm 0.14^{b}$ & $77.34 \pm 3.04^{\mathrm{a}}$ & $51.92 \pm 1.68^{a}$ & $88.52 \pm 3.82^{\mathrm{ab}}$ & $36.00 \pm 3.14^{\mathrm{d}}$ \\
\hline$+\mathrm{AMF}$ & $2.01 \pm 0.11^{\mathrm{a}}$ & $0.79 \pm 0.10^{\mathrm{a}}$ & $2.80 \pm 0.19^{\mathrm{a}}$ & $70.75 \pm 4.39^{b}$ & $57.08 \pm 0.37^{\mathrm{a}}$ & $97.74 \pm 5.25^{\mathrm{a}}$ & $45.16 \pm 3.21^{\mathrm{c}}$ \\
\hline EGTA-AMF & $0.25 \pm 0.03^{\mathrm{e}}$ & $0.24 \pm 0.04^{\mathrm{d}}$ & $0.49 \pm 0.01^{\mathrm{e}}$ & $44.37 \pm 2.58^{d}$ & $25.96 \pm 2.89^{c}$ & $59.82 \pm 8.44^{\mathrm{e}}$ & $28.34 \pm 2.31^{\mathrm{e}}$ \\
\hline $\mathrm{EGTA}+\mathrm{AMF}$ & $0.63 \pm 0.04^{\mathrm{d}}$ & $0.45 \pm 0.08^{c}$ & $1.09 \pm 0.09^{c}$ & $48.38 \pm 1.11^{\mathrm{d}}$ & $35.09 \pm 8.34^{\mathrm{b}}$ & $69.64 \pm 10.47^{\mathrm{de}}$ & $32.78 \pm 0.58^{\mathrm{de}}$ \\
\hline TFP-AMF & $0.62 \pm 0.02^{\mathrm{d}}$ & $0.18 \pm 0.03^{\mathrm{d}}$ & $0.80 \pm 0.03^{d}$ & $56.54 \pm 3.59^{c}$ & $36.90 \pm 1.94^{\mathrm{b}}$ & $75.92 \pm 1.80 c^{d}$ & $56.77 \pm 3.63^{a}$ \\
\hline $\mathrm{TFP}+\mathrm{AMF}$ & $0.81 \pm 0.03^{c}$ & $0.30 \pm 0.03^{\mathrm{d}}$ & $1.11 \pm 0.06^{\mathrm{c}}$ & $44.56 \pm 2.41^{\mathrm{d}}$ & $52.26 \pm 1.33^{\mathrm{a}}$ & $83.19 \pm 3.53^{\mathrm{bc}}$ & $50.05 \pm 1.80^{b}$ \\
\hline
\end{tabular}

Same letter within each column indicates no significant difference among treatments $(\mathrm{P}<0.05)$

not significant between TFP-AMF and TFP+AMF seedlings. In addition, EGTA and TFP applications notably decreased chlorophyll $a, b$, and $a+b$ concentrations than non-applied control, irrespective of AM or not.

\section{Sucrose and glucose concentrations}

In seedlings inoculated with AMF only, AM seedlings recorded significantly lower leaf sucrose concentration and higher root glucose concentration (Tab. 4). In seedlings applied by EGTA, inoculated seedlings showed significantly higher root sucrose concentration than un-inoculated seedlings. In seedlings applied by TFP, AM seedlings represented significantly higher root sucrose concentration but lower leaf sucrose and root glucose concentrations, as compared with non-AM seedlings. EGTA and TFP applications notably decreased leaf and root sucrose concentration and leaf glucose concentration, irrespective of AM or not, except a similar root sucrose between +AMF and TFP+AMF. In addition, addition of EGTA significantly decreased root glucose concentration but TFP markedly increased root glucose concentration than noinhibitor treatment.

\section{Discussion}

In a plant-AMF system, transient $\mathrm{Ca}^{2+}$ changes in plant cells have been released by AMF (Navazio and Mariani, 2008), implying that $\mathrm{Ca}^{2+}$ as a symbiotic signal is generated during AM formation (Navazio et al., 2007; Chabaud et al., 2011). Our study showed that exogenous EGTA (an inhibitor of $\mathrm{Ca}^{2+}$ ) significantly inhibited root AM colonization, soil hyphal length, and rhizospheric EE-GRSP and T-GRSP production, suggesting that $\mathrm{Ca}^{2+}$ might participate in AM establishment, soil hyphal growth, and release of GRSP fractions. On the other hand, TFP (an inhibitor of $\mathrm{CaM}$ ) did not alter soil hyphal length and rhizospheric T-GRSP level, but significantly decreased root AM colonization and increased EE-GRSP level, suggesting that $\mathrm{CaM}$ might involve only in the root AM development but not in the soil hyphal development and behaviour. It is well documented that $\mathrm{Ca}^{2+}$ acts as an upstream regulator for CaM (Liao et al., 2012). Therefore, CaM as the downstream product may less take part in the AMF-plantsoil system.

The present results showed that the exogenous applications of EGTA and TFP had negative effects on plant height, stem diameter, leaf number, and shoot and root biomass in $\mathrm{AM}$ and non-AM seedlings, which agrees with those obtained by Xu et al. (2009) and Ozgen et al.
(2011). Nevertheless, AMF inoculation significantly improved these growth traits under no-inhibitor, EGTA and TFP conditions than non-AMF treatment, indicating that AMF alleviated the inhibition of EGTA and TFP to plant growth in a certain extent. It seems that $\mathrm{CaM} / \mathrm{Ca}^{2+}$ mediated the functioning of AMF or vice-versa (Conn et al., 2011; Poovaiah et al., 2013).

$\mathrm{CaM}$ or $\mathrm{Ca}^{2+}$ as a signal transducer acts upon the development of lateral roots (Kanchiswamy et al., 2014). In the present study, the application of EGTA and TFP considerably limited the root total length, surface area, volume, and number of $1^{\text {st }}-, 2^{\text {nd }}$ - and $3^{\text {rd }}$-order lateral roots, which is in agreement with Muto and Hirosawa (1987). The result also suggested that $\mathrm{CaM}$ and $\mathrm{Ca}^{2+}$ closely connect with root growth, because $\mathrm{Ca}^{2+} / \mathrm{CaM}$ is involved in auxin-induced adventitious root development (Liao et al., 2012). Presence of AMF, in the present study, had the ability to alleviate or eliminate the negative effects of EGTA and TFP on root morphology. However, it is not clear whether the AM-mediated root improvement is related either with AM-induced $\mathrm{Ca}^{2+}$ and $\mathrm{CaM}$ levels or with improvement of nutrients by mycorrhization. In roots, CaM mainly distributed in cortical microtubules of root meristematic zone and in the root tip (Fraichard et al., 1996), where the AMF less colonized. The TFP application did not alter root total length and surface area, but increased root volume under mycorrhization and notably decreased root total length and surface area and did not alter root volume under non-mycorrhization. It seems that the presence of AMF has the ability to defend the CaM inhibitor, and therefore, better root development occurs in AM plants.

Our study showed that under no-inhibitor of $\mathrm{Ca}^{2+}$ or $\mathrm{CaM}$ conditions, AMF significantly enhanced chlorophyll $a, b$, and $a+b$ concentrations relative to non-AMF control, which is consistent with a previous study reported by Campanelli (2013). In addition, chlorophyll $a, b$, and $a+b$ concentrations were inhibited by exogenous applications of EGTA and TFP under non-mycorrhization, which agree with Lechowski and Bialczyk (1993). It implies that CaM and $\mathrm{Ca}^{2+}$ may be involved in the activity of chlorophyll composition. However, the integration of AMF with EGTA or TFP significantly increased these three chlorophyll concentrations than the EGTA/TFP-AMF, indicating that AMF could alleviate the negative effects of EGTA and TFP on activity of chlorophyll composition.

Mycorrhizal symbiosis would request 4-20\% of plant fixed carbohydrates for development, especially hexose (Finlay, 2008). In the present study, AMF inoculation 
generally significantly decreased leaf sucrose concentration but significantly increased root sucrose concentration, irrespective of inhibitor types, confirming that AMs might shift an allocation of sucrose to pools for cleaving (Wu et al., 2013b). Moreover, EGTA and TFP applications generally inhibited leaf and root sucrose concentrations, whilst AM presence altered the inhibited effects: decrease in leaf and increase in root, suggesting that AM-mediated sucrose modification was dependent on tissue position. Although EGTA and TFP significantly decreased leaf glucose, AMF could eliminate the negative effects of EGTA and TFP. It is well documented that AMF could induce cleavage of sucrose into glucose and fructose into the root (Wu et al., 2013b), thereby, triggering better translocation of glucose, leading to better root and shoot biomass yield. In the present study, root glucose was notably decreased by EGTA treatment but increased by TFP, whilst AMF inoculation did not significantly alter root glucose under EGTA but decreased under TFP and increased under no-inhibitor. These results illuminate that AM-induced root glucose modification might be regulated by $\mathrm{Ca}^{2+}$ or CaM. In addition, glucose not only controls root growth and development, but also modulates AM development (Mishra et al., 2009). As a result, higher glucose in AM leaf would benefit AM and root development. On the other hand, increasing concentration of root glucose under no-inhibitor and EGTA conditions and decreasing concentration of root glucose under TFP caused by mycorrhization may be due to the integration of $\mathrm{AMs}$ and $\mathrm{Ca}^{2+}$ or $\mathrm{CaM}$, which needs to be further studied.

\section{Conclusions}

The present study indicated that $\mathrm{Ca}^{2+}$ involved in root mycorrhizal colonization, soil hyphal development and GRSP production, and CaM involved in root colonization and GRSP production. AMF inoculation could reverse the negative effects of EGTA and TFP on plant growth performance, root traits, and chlorophyll concentrations, suggesting that AMF might mediate endogenous $\mathrm{Ca}^{2+}$ or $\mathrm{CaM}$ for normal physiology. Plant carbohydrates would be altered by the integration with EGTA and TFP or AMF inoculation, which might benefit root and shoot biomass production.

\section{Acknowledgements}

This study was supported by the Excellent Young Teacher Research Support Program of Yangtze University (cyq201324) of China.

\section{References}

Bethlenfalvay GJ, Ames RN (1987). Comparison of two methods for quantifying extraradical mycelium of vesicular arbuscular mycorrhizal fungi. Soil Sci Soc Am J 51:834-837.

Breuninger M, Requena N (2004). Recognition events in AM symbiosis: analysis of fungal gene expression at early appressorium stage. Fungal Genet Biol 41:794-804.

Campanelli A, Ruta C, de Mastro G, Morone-Fortunato I (2013). The role of arbuscular mycorrhizal fungi in alleviating salt stress in Medicago sativa L. var. icon. Symbiosis 59:65-76.

Chabaud M, Genre A, Sieberer BJ, Faccio A, Fournier J, Novero M, Barker DG, Bonfante P (2011). Arbuscular mycorrhizal hyphopodia and germinated spore exudates trigger $\mathrm{Ca}^{2+}$ spiking in the legume and nonlegume root epidermis. New Phytol 189:347-355.

Conn S, Gilliham M, Athman A, Schreiber AW, Baumann U, Moller I, Cheng NH, Stancombe MA, Hirschi KD, Webb AA, Burton R, Kaiser BN, Tyerman SD, Leigh RA (2011). Cell-specific vacuolar calcium storage mediated by CAX1 regulates apoplastic calcium concentration, gas exchange, and plant productivity in Arabidopsis. Plant Cell 23:240-257.

Dodd AN, Kudla J, Sanders D (2010). The language of calcium signaling. Annu Rev Plant Biol 61:593-620.

Finlay RD (2008). Ecological aspects of mycorrhizal symbiosis: with special emphasis on the functional diversity of interactions involving the extraradical mycelium. J Exp Bot 59:1115-1126.

Fraichard A, Perotti E, Gavin O, Chanson A (1996). Subcellular localization, distribution and expression of calmodulin in Zea mays roots. Plant Sci 118:157-165.

Harrison MJ (2005). Signaling in the arbuscular mycorrhizal symbiosis. Annu Rev Microbiol 59:19-42.

Hetherington AM, Browlee C (2004). The generation of $\mathrm{Ca}^{2+}$ signals in plants. Annu Rev Plant Biol 55:401-427.

Kanchiswamy CN, Malnoy M, Occhipinti A, Maffei ME (2014). Calcium imaging perspectives in plants. Int J Mol Sci 15:38423859.

Kivlin SN, Hawkes CV, Treseder KK (2011). Global diversity and distribution of arbuscular mycorrhizal fungi. Soil Biol Biochem 43:2294-2303.

Lechowski Z, Bialczyk J (1993). Calcium mediated cytokinin action on chlorophyll synthesis in isolated embryo of Scots pine. Biol Plant 35:53-62.

Liao WB, Zhang ML, Huang GB, Yu JH (2012). $\mathrm{Ca}^{2+}$ and CaM are involved in $\mathrm{NO}$ - and $\mathrm{H}_{2} \mathrm{O}_{2}$-induced adventitious root development in marigold. J Plant Growth Regul 31:253-264.

Lichtenthaler HK, Wellburn AR (1983). Determination of total carotenoids and chlorophyll a and $\mathrm{b}$ of leaf extracts in different solvents. Biochem Soc Trans 603:591-603.

Lopez-Bucio J, Cruz-Ramirez A, Herrera-Estrella L (2003). The role of nutrient availability in regulating root architecture. Curr Opin Plant Biol 6:280-287.

Maillet F, Poinsot V, Andre O, Puech-Pages V, Haouy A, Gueunier M, Cromer L, Giraudet D, Formey D, Niebel A, Martinez EA, Driguez H, Becard G, Denarie J (2011). Fungal lipochitooligosaccharide symbiotic signals in arbuscular mycorrhiza. Nature 469:58-63.

Mishra BS, Singh M, Laxmi A (2009). Glucose and auxin signaling interaction in controlling Arabidopsis thaliana seedlings root growth and development. PLoS ONE 4:e4502.

Muto S, Hirosawa T (1987). Inhibition of adventitious root growth in tradescantia by calmodulin antagonists and calcium inhibitors. Plant Cell Physiol 28:1569-1574. 
385

Navazio L, Mariani P (2008). Calcium opens the dialogue between plants and arbuscular mycorrhizal fungi. Plant Signal Behav 3:229-230.

Navazio L, Moscatiello R, Genre A, Novero M, Baldan B, Bonfante P, Mariani P (2007). A diffusible signal from arbuscular mycorrhizal fungi elicits a transient cytosolic calcium elevation in host plant cells. Plant Physiol 144:673681.

Ozgen S, Busse JS, Palta JP (2011). Influence of root zone calcium on shoot tip necrosis and apical dominance of potato shoot: simulation of this disorder by ethylene glycol tetra acetic acid and prevention by strontium. HortScience 46(10):1358-1362.

Phillips JM, Hayman DS (1970). Improved procedures for clearing roots and staining parasitic and vesicular-arbuscular mycorrhizal fungi for rapid assessment of infection. Trans $\mathrm{Br}$ Mycol Soc 55:158-161.

Poovaiah BW, Du LQ, Wang HZ, Yang TB (2013). Recent advances in calcium/calmodulin-mediated signaling with an emphasis on plant-microbe interactions. Plant Physiol 163: 531-542.

Wu QS, Li GH, Zou YN (2011). Roles of arbuscular mycorrhizal fungi on growth and nutrient acquisition of peach (Prunus persica L. batsch) seedlings. J Anim Plant Sci 21:746-750.

Wu QS, Srivastava AK, Zou YN (2013a). AMF-induced tolerance to drought stress in citrus: A review. Sci Hortic 164:77-87.
Wu QS, He XH, Zou YN, Liu CY, Xiao J, Li Y (2012). Arbuscular mycorrhizas alter root system architecture of Citrus tangerine through regulating metabolism of endogenous polyamines. Plant Growth Regul 68:27-35.

Wu QS, Zou YN, Huang YM, Li Y, He XH (2013b). Arbuscular mycorrhizal fungi induce sucrose cleavage for carbon supply of arbuscular mycorrhizas in citrus genotypes. Sci Hortic 160:320-325.

Xu T, Li TL, Qi MF (2009). Calcium effects on mediating polygalacturonan activity by mRNA expression and protein accumulation during tomato pedicel explants abscission. Plant Growth Regul 60:255-263.

Zamioudis C, Mastranesti P, Dhonukshe P, Blilou I, Pieterse CMJ (2013). Unraveling root developmental programs initiated by beneficial Pseudomonas spp. bacteria. Plant Physiol 162:304318.

Zhang ZL, Zai LJ (2004). Experimental Instruction of Plant Physiology. 3rd ed. Higher Education Press, Beijing, 328 p.

Zou YN, Srivastava AK, Wu QS, Huang YM (2014). Glomalinrelated soil protein and water relations in mycorrhizal citrus (Citrus tangerina) during soil water deficit. Arch Agron Soil Sci 60:1103-1114. 